\title{
A spatio-temporal dataset of forest mensuration for the analysis of tree species structure and diversity in semi-natural mixed floodplain forests
}

\author{
Most Jannatul Fardusi ${ }^{1,2} \cdot$ Cristiano Castaldi $^{2} \cdot$ Francesco Chianucci $^{3} \cdot$ Piermaria Corona $^{2} \cdot$ Franco Mason $^{4}$. \\ Emma Minari ${ }^{5} \cdot$ Nicola Puletti $^{6}$
}

Received: 20 March 2017 / Accepted: 31 December 2017 / Published online: 23 January 2018

(C) The Author(s) 2018. This article is an open access publication

Keywords Point pattern analysis · Tree-level forest inventory $\cdot$ Spatio-temporal analysis $\cdot$ Spatial diversity $\cdot$ Tree diversity

\section{Background}

Analyses of tree structure and diversity have traditionally employed non-spatial measures, due to the simplicity of such approach (e.g. Neumann and Starlinger 2001). However, over the last few decades, a large number of studies have been performed to quantify tree structure and diversity in a spatially explicit way (e.g. Aguirre et al. 2003; Pommerening 2002; Pommerening 2006; Hui and Pommerening 2014). Results from these studies have led to the safe conclusion that spatially explicit measures provide more information on biodiversity patterns in forests compared with non-spatial measures. At another level, functional diversity approach allows integrating ecosystem processes and diversity analyses (Laliberté and Legendre 2010).

Most Jannatul Fardusi, Cristiano Castaldi, Francesco Chianucci, Piermaria Corona, Franco Mason, Emma Minari and Nicola Puletti contributed equally to this work.

Key message We performed replicated, repeated measures of height, diameter and vitality at tree level to allow analysis of spatial and temporal structure and diversity in a semi-natural-mixed floodplain forest in Italy. Three inventories were performed in 1995, 2005 and 2016 in three $\sim 1$ ha plots with varying soil moisture regimes. The use of replicated, repeated measures data rather than chronosequences allows the examination of true changes in spatial pattern processes through time in this forest type. Dataset access at https://doi.org/10.17632/n8827ssnv7.2. Associated metadata available at https://metadata-afs.nancy.inra.fr/geonetwork/srv/ fre/catalog.search\#/metadata/65ec7cd7-ca6a-4ade-94dd-d8ce0b107f3e

Handling Editor: Marianne Peiffer

Electronic supplementary material The online version of this article (https://doi.org/10.1007/s13595-018-0688-8) contains supplementary material, which is available to authorized users.

Most Jannatul Fardusi

jfardusi@unitus.it

Extended author information available on the last page of the article
Recently, the functional diversity approach has been included in forestry studies (e.g. Hui and Pommerening 2014).

Mixed forests are particularly interesting for diversity analyses, as high diversity can be expected in this forest type (BravoOviedo et al. 2014). Repeated spatio-temporal analysis in these forests may provide insight on natural stand development processes over time. However, because of cost and time constraints, very few studies have performed spatial-temporal analysis of forest stands dynamics (e.g. LeMay et al. 2009). In addition, most studies employed chronosequences rather than true time series (repeated measures on permanent plots), which may introduce some uncertainties in interpreting trends over time. Further, the majority of previous studies on spatial diversity has analysed tropical and sub-tropical forests (Wright 2002; Wiegand et al. 2007), while studies on temperate forests have been scarce (e.g. Hui and Pommerening 2014).

Semi-natural Reserve of Bosco Fontana is one of the last remaining floodplain forests in the Northern Italy (Zapponi et al. 2014) and one of the most endangered ecosystems in Europe (Schlaghamersky 2000). The forest has been managed as coppice with standards until the 80 s and then it was left to develop naturally. The high level of diversity and naturalness of the stands makes this forest an ideal site for studying structure and dynamics in mixed floodplain forests.

The dataset presented here provide replicated, repeated measurements at single-tree level conducted in three $\sim 1$-ha permanent plots; all standing trees in these plots were mapped and inventoried in 1995, 2005, and 2016. These data can be used to perform temporal analysis of tree structure and diversity in this forest type enabling both non-spatial and spatially explicit measures to be employed. 


\section{Methods}

The data were collected in Bosco Fontana, a State Natural Reserve in Northern Italy $\left(45^{\circ} 12^{\prime} \mathrm{N}, 10^{\circ} 44^{\prime} \mathrm{E}\right)$, which belong to the Long-Term Ecosystem Research network (https://data. lter-europe.net/deims/site/LTER_EU IT 037). The climate is continental, with long, cold winters and hot, humid summers. The average annual temperature is $13.2{ }^{\circ} \mathrm{C}$, and the average annual rainfall was $658 \mathrm{~mm}$ (Campanaro et al. 2007). Eightyfive percent of the Reserve is covered by a semi-natural forest (Mason 2002, 2004) belonging to the Sub-Atlantic and medio-European oak-hornbeam forests of the Carpinion betuli (code 9160, Habitats Directive-1992/43/CEE), European Forest Type 5.1 (Pedunculate oak-hornbeam forests; Barbati et al. 2014).

Three $\sim 1$-ha $(140 \mathrm{~m} \times 70 \mathrm{~m})$ permanent plots (hereafter Core Areas, abbreviated CA) were established in 1995 as representative of the variation in stand structure and composition of the mixed oak-hornbeam forests covering the Natural Reserve (Mason and Minari 2009). Specifically, CA1, CA2 and $\mathrm{CA} 3$ represent the xeric, mesic and moist regime variant of the oak-hornbeam forest, which were classified based on soil moisture measurements (Mason 2004). These stands were managed as coppice with standards until the $80 \mathrm{~s}$ and then left to develop towards high-forestry system (Mason 2004). The sampling protocol follows the SILVI-STAR nested protocol by Koop (1989). Three additional plots were also surveyed in another study, but they were not added in the current dataset as their plot size was smaller $(0.1 \mathrm{ha})$ than the three CAs, and the forest inventories were limited to 1995 and 2005 in these plots (Chianucci et al. 2016).

Each CA was divided into $10 \times 10 \mathrm{~m}$ sub-plots (Fig. 1), in which all standing trees (individuals with a stem diameter at $1.30 \mathrm{~m} \geq 5 \mathrm{~cm}$ ) were labelled, their species identified, and their position mapped using a total station (an electronic distance measurement instrument for coordinate calculation) and georeferenced in a relative $\mathrm{X}$ and $\mathrm{Y}$ coordinate system (Fig. 1). For each standing tree, the following parameters were recorded: species, diameter at breast height $(1.30 \mathrm{~m})$, total height and vitality (alive tree/dead tree). Standing tree measurements were carried out in three inventories made in winter 1995, 2005 and 2016 and included in the dataset. A total of 5015 trees were included in the dataset.

\section{Data access and metadata description}

The dataset ('dataset_Bosco_Fontana.csv') is available using the following reference and doi: Fardusi et al. (2017), a spatiotemporal dataset of forest mensuration for the analysis of tree species structure and diversity in semi-natural mixed floodplain forests, V2, Mendeley data [dataset] https://doi.org/10. 17632/n8827ssnv7.2 under the Creative Commons
Core Area (CA)

\begin{tabular}{|c|c|c|c|c|c|c|}
\hline 14 & 15 & 42 & 43 & 70 & 71 & 98 \\
\hline 13 & 16 & 41 & 44 & 69 & 72 & 97 \\
12 & 17 & 40 & 45 & 68 & 73 & 96 \\
\hdashline 11 & 18 & 39 & 46 & 67 & 74 & 95 \\
\hdashline 10 & 19 & 38 & 47 & 66 & 75 & 94 \\
\hdashline 9 & 20 & 37 & 48 & 65 & 76 & 93 \\
\hline 8 & 21 & 36 & 49 & 64 & 77 & 92 \\
\hline 7 & 22 & 35 & 50 & 63 & 78 & 91 \\
\hdashline 6 & 23 & 34 & 51 & 62 & 79 & 90 \\
\hdashline 5 & 24 & 33 & 52 & 61 & 80 & 89 \\
\hdashline 4 & 25 & 32 & 53 & 60 & 81 & 88 \\
\hdashline 3 & 26 & 31 & 54 & 59 & 82 & 87 \\
\hline 2 & 27 & 30 & 55 & 58 & 83 & 86 \\
\hline 1 & 28 & 29 & 56 & 57 & 84 & 85 \\
\hline 0 & & & & & $70 \mathrm{~m}$ \\
\hline
\end{tabular}

Fig. 1 Characteristics of the surveyed permanent plots (Core AreasCAs). The number indicates the $10 \times 10$ sub-plot squares (labelled as 'Square no' field in the dataset)

Attribution-Non Commercial 4.0 Licence. Table 1 lists the variables contained in the dataset. For each variable, a data dictionary in text format is also provided as supplementary material, which comprises a complete list of the tables in the dataset, the data format and the description of each variable.

Associated metadata available at https://metadata-afs. nancy.inra.fr/geonetwork/srv/fre/catalog.search\#/metadata/ 65ec7cd7-ca6a-4ade-94dd-d8ce0b107f3e. The metadata includes several tables, including (1) a documentation on data provision and discovery, (2) information on the origin and context of the dataset, (3) a technical documentation of the meaning of all variable names and (4) the key code tables for the list variables (see Table 1).

\section{Technical validation}

Data cleansing has been performed to check for data quality. Data inconsistency that may have been originating by errors in user entry (e.g. typographical errors), data type storage and 
Table 1 Variables reported in the dataset

\begin{tabular}{|c|c|c|c|c|c|}
\hline Variable name & Variable definition & Units & Data type & Range & List variable \\
\hline $\mathrm{CA}$ & Core area number & & Text & $1-3$ & Yes \\
\hline Square_no & Number of $10 \times 10$ sub-plot square & & Integer number & $1-98$ & \\
\hline Treeid & Reference tree identification number & & Integer number & $1-929$ & \\
\hline Inv_year & Inventory year & & Integer number & $1-3$ & Yes \\
\hline Id_old & $\begin{array}{l}\text { Tree identification number used } \\
\text { during field measurements (may include } \\
\text { letters in case of stools) }\end{array}$ & & Text & & \\
\hline VIT & Vitality condition of tree & & Integer number & $1-2$ & Yes \\
\hline SP & Species abbreviation code & & Text & & Yes \\
\hline $\mathrm{BX}$ & $\mathrm{X}$-coordinate of tree & $\mathrm{m}$ & Float number & $0-70$ & \\
\hline BY & Y-coordinate of tree & $\mathrm{m}$ & Float number & $0-140$ & \\
\hline $\mathrm{TH}$ & Tree height & $\mathrm{m}$ & Float number & $1.3-36.9$ & \\
\hline DBH & Tree diameter measured at $1.3 \mathrm{~m}$ (breast height) & $\mathrm{cm}$ & Float number & $5.0-96.5$ & \\
\hline
\end{tabular}

field measurements has been checked by two independent expert users. Example of analysis of data quality included data type constraints (e.g. values in a field must meet the desired data type), range constraints (minimum and maximum values allowed for numerical variables), numeric constraints (e.g. the diameter must not decrease through time), unique constraints (e.g. the same trees must have the same species code in the different inventories).
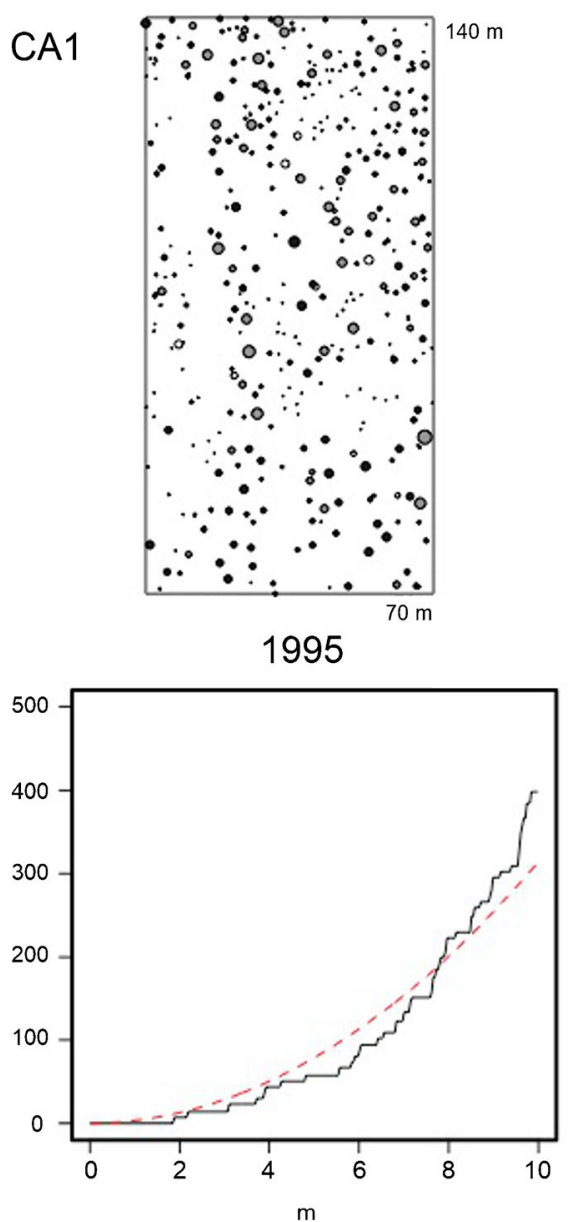
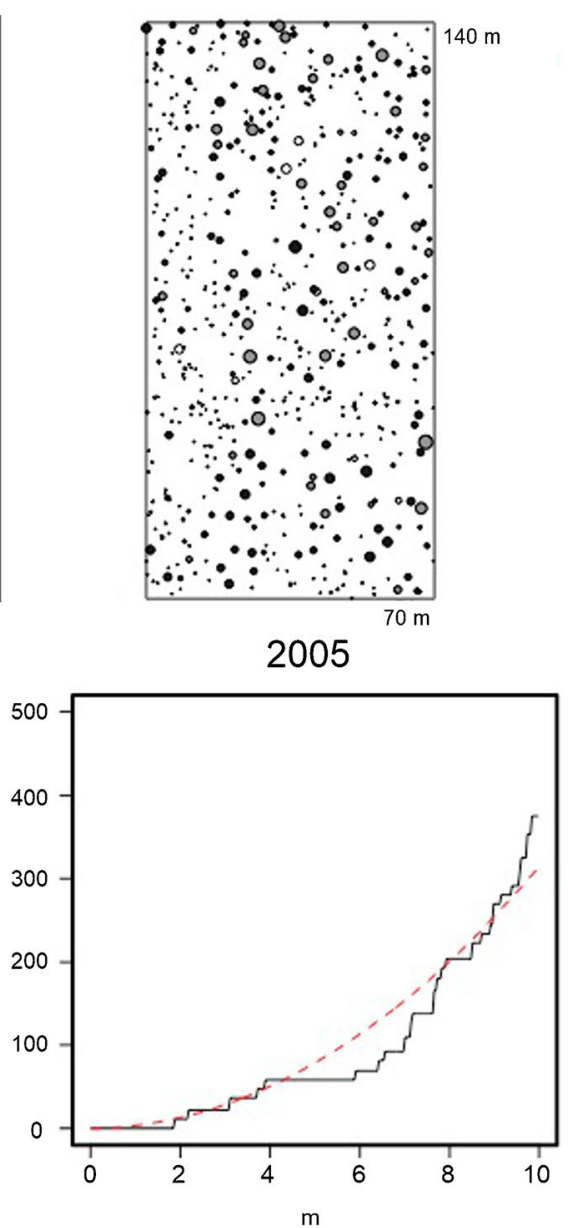
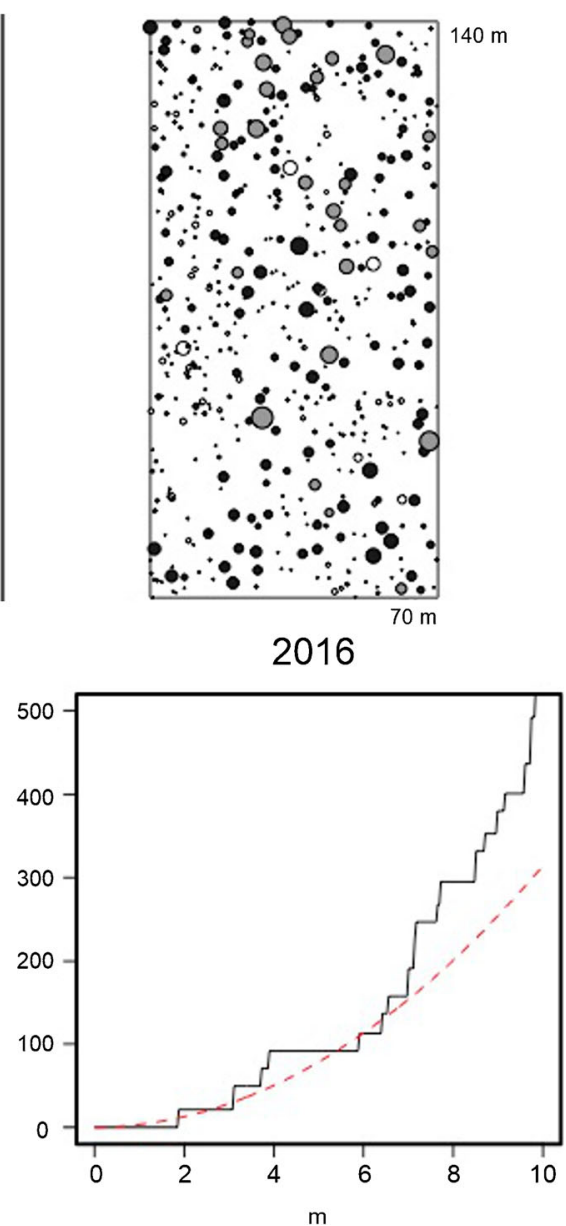

Fig. 2 An example of tree mapping of the Core Area 1 in the three inventories (above) and the Ripley's K( $r$ ) function (below). Ripley's K describes if the phenomenon of interest (e.g. trees distribution) appears to be dispersed, clustered, or randomly distributed throughout the study area 


\section{Reuse potential and limits}

Although the data collection has been limited to three plots, the spatio-temporal resolution of data allows a various set of forest-related indices, useful to describe ecological dynamics (Neumann and Starlinger 2001). In addition, sampling design allows integration of this dataset with other ones available from previous studies (e.g. Aguirre et al. 2003; Hui and Pommerening 2014; LeMay et al. 2009), useful for comparative, large-scale studies.

The data allowed a traditional set of forest parameters to be extracted like stand variables (stocking rate, basal area, species composition, dominant height, mean diameter). Volumes could be easily calculated with 'ForIT' package of R (Puletti et al. 2017), which implements all volume equations used for the last Italian National Forest Inventory.

A wide range of diversity measures can be computed from the dataset, including traditional, non-spatial measures (species richness, Shannon Index, Simpson Index) and spatialmeasures; the latter includes single tree neighbouring indices, distance-dependent stand indices and continuous functions (for details, see Pommerening 2002); an example is given in Fig. 2 with Ripley's K(r) function. Ripley's K $(r)$ function or related functions have been often used to examine spatial point patterns in forest environments (e.g. Perry et al. 2006). The dataset format (comma separated value file, easily convertible in a text file format) allows calculation of such indices from the CRANCOD program developed by Arne Pommerening (http://www.pommerening.org/wiki/index. php?title=CRANCOD___A_Program_for_the_Analysis and_Reconstruction_of_Spatial_Forest_Structure) or using a statistical program such as $\mathrm{R}$ enviroment, using for example the 'spatstat' package (Baddeley et al. 2015).

Data on species composition can also be used as community-weighted means information to compute functional diversity indices. The dataset format allows computation of functional diversity indices using the 'FD' package of R (Laliberté and Legendre 2010) integrating species abundances with functional traits available from literature or using the 'TR8' package of R (Bocci 2015). An example of such approach is described in Chianucci et al. (2016).

Extension of spatial analyses to include changes in time allows the examination of changes in stand structure due to mortality, growth, regeneration and competition (LeMay et al. 2009). In this line, the relevant strength of the dataset is that it allows performing an integrated set of tree structure and diversity analyses at both spatial and temporal scales. To date, no comparable spatio-temporal measurements were provided for mixed broadleaved forests. This information may strengthen the knowledge of structure, diversity and species interactions naturally occurring in mixed broadleaved forests, e.g. supporting the design of silvicultural practices able to mimic the patterns and processes of natural disturbances by creating and maintaining stand structure heterogeneity (Angelini et al. 2015). Finally, we foresee to periodically replicate tree inventory measurements at 10-year interval, so we plan to include new measurements once they will be made available in future field campaigns.

Acknowledgements We dedicated this study to the memory of Muhammad Muddasir (1986-2017). We are grateful to the anonymous reviewers and handling Editor, which helped to improve the manuscript with their comments.

Funding Most Jannatul Fardusi was supported by a Ph.D. in Forest Ecology and Environmental Technologies (XXXI Cycle) at Department for the Innovation in Biological, Agro-food and Forest systems, Università degli Studi della Tuscia. Francesco Chianucci and Nicola Puletti were supported by the Project 'ALForLab' (PON03PE 00024 1) co-funded by the Italian Operational Programme for Research and Competitiveness (PON R\&C) 2007-2013, through the European Regional Development Fund (ERDF) and national resource (Revolving Fund-Cohesion Action Plan (CAP) MIUR).

Open Access This article is distributed under the terms of the Creative Commons Attribution 4.0 International License (http:// creativecommons.org/licenses/by/4.0/), which permits unrestricted use, distribution, and reproduction in any medium, provided you give appropriate credit to the original author(s) and the source, provide a link to the Creative Commons license, and indicate if changes were made.

\section{References}

Aguirre O, Hui G, von Gadow K, Jiménez J (2003) An analysis of spatial forest structure using neighbourhood-based variables. For Ecol Manag 183(1-3):137-145. https://doi.org/10.1016/S0378-1127(03) 00102-6

Angelini A, Corona P, Chianucci F, Portoghesi L (2015) Structural attributes of stand overstory and light under the canopy. Ann Silvicultural Res 39:23-31

Baddeley A, Rubak E, Turner R (2015) Spatial point patterns: methodology and applications with R. London: Chapman and Hall/CRC Press, 2015. URL http://www.crcpress.com/Spatial-Point-PatternsMethodology-and-Applications-with-R/Baddeley-Rubak-Turner/ 9781482210200

Barbati A, Marchetti M, Chirici G, Corona P (2014) European forest types and forest Europe SFM indicators: tools for monitoring progress on forest biodiversity conservation. For Ecol Manag 321:145157. https://doi.org/10.1016/j.foreco.2013.07.004

Bocci G (2015) TR8: an R package for easily retrieving plant species traits. Methods Ecol Evol 6(3):347-350. https://doi.org/10.1111/ 2041-210X.12327

Bravo-Oviedo A, Pretzsch H, Ammer C, Andenmatten E, Antón C, Barbati A, Barreiro S, Brang P, Bravo F, Brunner A, Coll L, Corona P, den Ouden J, Drössler L, Ducey MJ, Kaynas BY, Legay M, Löf M, Lesinski J, Mason B, Meliadis M, Manetti MC, Morneau F, Motiejunaite J, O'Reilly C, Pach M, Ponette Q, Río M, Short I, Skovsgaard JP, Souidi Z, Spathelf P, Sterba H, Stojanovic D, Strelcova K, Svoboda M, Valsta L, Verheyen K, Zlatanov T (2014) European mixed forests: definition and perspectives. Forest Syst 3:518-533

Campanaro A, Hardersen S, Mason F (2007) Piano di gestione della Riserva Naturale Statale e Sito Natura 2000 "Bosco Fontana" [management plan of the state natural reserve and nature 2000 site "Bosco 
Fontana"]. Quaderni Conservazione Habitat 4, Cierre edizioni, Verona, Italy, pp. 220. [in Italian]

Chianucci F, Minari E, Fardusi MJ, Merlini P, Cutini A, Corona P, Mason F (2016) Relationships between overstory and understory structure and diversity in semi-natural mixed floodplain forests at Bosco Fontana (Italy). iForest 9(6):919-926. https://doi.org/10.3832/ ifor1789-009

Fardusi MJ, Castaldi C, Chianucci F, Corona P, Minari E, Mason F, Puletti N (2017) A spatio-temporal dataset of forest mensuration for the analysis of tree species structure and diversity in seminatural mixed floodplain forests, V2, mendeley data [dataset]. https://doi.org/10.17632/n8827ssnv7.2

Hui G, Pommerening A (2014) Analysing tree species and size diversity patterns in multi-species uneven-aged forests of Northern China. For Ecol Manag 316:125-138. https://doi.org/10.1016/j.foreco.2013.07. 029

Koop H (1989) Forest dynamics: SILVI-STAR, a comprehensive monitoring system. Springer-Verlag, Berlin $229 \mathrm{pp}$

Laliberté E, Legendre P (2010) A distance-based framework for measuring functional diversity from multiple traits. Ecology 91(1):299 305. https://doi.org/10.1890/08-2244.1

LeMay V, Pommerening A, Marshall P (2009) Spatio-temporal structure of multi-storied, multi-aged interior Douglas fir (Pseudotsuga menziesii var. glauca) stands. J Ecol 97(5):1062-1074. https://doi. $\operatorname{org} / 10.1111 / \mathrm{j} .1365-2745.2009 .01542 . x$

Mason F (2002) Dinamica di una foresta della Pianura Padana. Bosco della Fontana - Primo contributo. Centro Nazionale Biodiversità Forestale Verona Bosco Fontana. Rapporti scientifici 1. Monitoraggio 1995. Arcari Editore. Mantova, 208 pp

Mason F (2004) Dinamica di una foresta della Pianura Padana, Bosco della Fontana. Seconda edizione con linee di gestione forestale. Centro Nazionale per lo Studio e la Conservazione Biodiversità
Forestale Verona Bosco della Fontana. Corpo Forestale dello Stato. Rapporti Scientifici. 1 2004. Arcari Editore, Mantova, 224 pp

Mason F, Minari E (2009) La teoria silvigenetica di Oldeman nella gestione delle aree protette. Atti del Terzo Convegno Nazionale di Selvicoltura 16-19 ottobre 2088. Taormina (Messina). Volume 3

Neumann M, Starlinger F (2001) The significance of different indices for stand structure and diversity in forests. For Ecol Manag 145(1-2): 91-106. https://doi.org/10.1016/S0378-1127(00)00577-6

Perry GLW, Miller BP, Enright NJ (2006) A comparison of methods for the statistical analysis of spatial point patterns in plant ecology. Plant Ecol 187(1):59-82. https://doi.org/10.1007/s11258-006-9133-4

Pommerening A (2002) Approaches to quantifying forest structures. Forestry 75(3):305-324. https://doi.org/10.1093/forestry/75.3.305

Pommerening A (2006) Evaluating structural indices by reversing forest structural analysis. For Ecol Manag 224(3):266-277. https://doi.org/ 10.1016/j.foreco.2005.12.039

Puletti N, Castaldi C, Marchi M, Scotti R (2017) ForlT: functions from the 2nd Italian forest inventory (INFC). https://github.com/cran/ ForIT/blob/master/R/ForIT-package.R

Schlaghamersky J (2000) The saproxylic beetles (Coleoptera) and ants (Formicidae) of central European hardwood floodplain forests. Folia Fac Sci Nat Univ Masaryk Brun, pp 103

Wiegand T, Gunatilleke CVS, Gunatilleke IAUN, Huth A (2007) How individual species structure diversity in tropical forests. PNAS 104(48):19029-19033. https://doi.org/10.1073/pnas.0705621104

Wright SJ (2002) Plant diversity in tropical forests: a review of mechanisms of species coexistence. Oecologia 130(1):1-14. https://doi. org/10.1007/s004420100809

Zapponi L, Minari E, Longo L, Toni I, Mason F, Campanaro A (2014) The habitat trees experiment: using exotic tree species as new microhabitats for the native fauna. iForest 8:464-470

\section{Affiliations}

\section{Most Jannatul Fardusi ${ }^{1,2} \cdot$ Cristiano Castaldi $^{2} \cdot$ Francesco Chianucci $^{3} \cdot$ Piermaria Corona $^{2} \cdot$ Franco Mason $^{4}$. Emma Minari ${ }^{5} \cdot$ Nicola Puletti $^{6}$}

1 Consiglio per la ricerca in agricoltura e l'analisi dell'economia agraria-Research Centre for Forestry and Wood, Arezzo, Italy

2 Department for the Innovation in Biological, Agro-food and Forest Systems, Università degli Studi della Tuscia, Viterbo, Italy

3 Consiglio per la ricerca in agricoltura e l'analisi dell'economia agraria-Research Centre for Agriculture and Environment, Rome, Italy

4 National Forest Service, National Center for Study and Conservation of Forest Biodiversity "Bosco Fontana", National Taxonomic Laboratory for Invertebrates, Verona, Italy
5 National Forest Service, National Center for the Study and Conservation of Forest Biodiversity "Bosco Fontana”, Marmirolo, Mantova, Italy

6 Consiglio per la Ricerca in Agricoltura e l'Analisi dell'Economia Agraria-Research Centre for Forestry and Wood, Villazzano, Trento, Italy 